
\title{
R Research Soure \\ Occupational Categorization of female Work Force in Kashmir Himalayas, India
}

\author{
Aisha Dev \\ University of Kashmir \\ M. Imran Ganaie ( $\nabla$ emraanmohmad@gmail.com ) \\ University of Kashmir https://orcid.org/0000-0002-9291-6870 \\ Dar Abida \\ University of Kashmir \\ Ishtiaq A. Mayer \\ University of Kashmir \\ Harmeet Singh \\ University of Kashmir
}

\section{Research Article}

Keywords: Occupational classification, Female workforce, Standard Deviation, Economic sectors, Kashmir Valley

Posted Date: August 23rd, 2021

DOl: https://doi.org/10.21203/rs.3.rs-835362/v1

License: (c) (i) This work is licensed under a Creative Commons Attribution 4.0 International License.

Read Full License 


\title{
Occupational Categorization of female Work Force in Kashmir Himalayas, India
}

\begin{abstract}
Occupational classification has been a subject of many experiments. From the definition of a worker to their attribution to a particular category of occupation. Multiple attempts have been made in understanding and explaining the same. The present paper attempts to take the case of female workforce and delves into the subject of categorizing their prevalence across the Kashmir valley (geographic unit), which by and large corresponds to Kashmir Division (administrative unit) in a comprehensible manner. The researcher adopts the Standard deviation method to do so. Using the standard deviations observed for each occupational category, the researcher proposes a rank table visualizing the target area employing a standard deviation-based occupational coding. Based on the rank table it is observed that amongst the female workforce the primary sector is dominant in Ganderbal and Kulgam districts, secondary sector in Shopian, Pulwama and Kulgam, tertiary sector in Srinagar and Budgam and the Quaternary/Quinary sectors in Srinagar, Anantnag and Pulwama districts. The standard deviation method adopted in this paper has led to a satisfactory representation of the occupational distribution observed in the sample area. The occupational coding of the target districts using this method not only makes it easier to visualize the occupational trends but also gives us a clear sense of variation (positive and negative) amongst these categories across the districts.
\end{abstract}

Keywords Occupational classification; Female workforce; Standard Deviation; Economic sectors; Kashmir Valley.

\section{Introduction}

Historians usually couch statements about social stratification and social mobility in terms of occupational structure. To trace the movements of a man from occupation to occupation is, to a considerable extent, to trace his vertical movement within social space. The sum of those movements determines the patterns and rate of mobility, the degree of openness, within a region (Katz et al., 1972). Occupational distribution plays a crucial role in global as well as in Indian economy. The occupational distribution of population reflects on the degree and level of development and the diversification achieved in a particular region. After the Industrial Revolution and also in recent times, the East and South-East Asia have been witnessed by the process of development associated with two types of transitions; (a) the movement of workforce from agriculture to manufacturing and services, and (b) migration from rural to urban areas, i.e., urbanization.

However, these transitions and mobility along with increased education, improving health is also associated with falling fertility rates and other socio-economic aspects (Kumar et al., 2018). It is argued that the Female workforce participation along with their role in society would play a critical role in the development process (Kumar, 2018). The task of analysing the occupational distribution of the working women in India has usually been avoided by experts in the past, and for quite genuine reasons as (Daniel et al., 1961) have summed up such types of difficulties in this regard as follows: "In every Census enumeration of India since 1881, the occupational figures for females are more difficult to interpret than those for males. To a large extent, in the Indian family economy, the role of women has been and still is auxiliary to that of the men. Accordingly, it has always been hard to draw the line 
between those whose economic contribution has been substantial and those whose work is considered more fruitful; apart from domestic duties of females, their job has been considered as minor or negligible. Variations from Census to Census, either in total female working force or in the number of women recorded as engaged in particular occupations, may reflect shifts in enumeration practice as much as genuine economic changes (Gulati, 1975).

Over the decades, the Indian Census has experimented with various definitions of the concept of a worker. At least part of this experimentation was aimed to get a correct measure of women's work participation. The 1971 Census change was probably directed at women. Consequently, the impact of the definitional change in 1971 on the female participation rate has been much larger than on the male participation rate. The result thus has been to cause further disgust among experts, particularly those wanting to study changes over time (Agarwal, 1985). Empowerment of women can accelerate economic development and discrimination against them can hinder the same, as there is a bidirectional relationship between empowerment of women and economic development.

Characterizing the workers is a longstanding and core issue. Traditionally, classification has been done manually. Many attempts have been made by geographers and other workers in the urban field to classify towns and cities according to the functions (El-Bushra, 1969). This paper aims to analyze the role of female workforce and to classify the female workforce into different occupational categories in relation to male workers. It is important to mention that the census of India only gives broad classifications i.e., (cultivators, agricultural labourers, household workers and others) the above grouping (i.e., into cultivation, agricultural labour and other work) does not follow the usual economic classification by sectors (i.e., primary, secondary and tertiary). Under the latter classification, all those engaged in mining, quarrying, livestock, forestry, fishing, hunting, plantations, orchards, and allied activities would qualify for inclusion in the primary sector. But under the Census classification followed here, all of them are banded with other non-agricultural workers (Gulati, 1975). This paper focuses on the further division of the "other sector" i.e., tertiary, quaternary and quinary. Furthermore, this paper attempts to rank the subdivisions of the sample area on the basis of representation of female workforce across the identified occupational categories, arriving at coding that comprehensively summarizes the distribution.

\section{Study Area}

The Kashmir Valley, also known as the Vale of Kashmir, is an intermontane valley in Kashmir. The valley is bounded on the southwest by the Pir Panjal Range and the northeast by the Himalayan range. It is approximately $135 \mathrm{~km}$ (84 miles) long and $32 \mathrm{~km}$ (20 miles) wide, and is drained by the river Jhelum. Kashmir Valley lies between latitude $32^{\circ}$ and $34^{\circ} \mathrm{N}$, and longitude $74^{\circ}$ and $75^{\circ} \mathrm{E}$ (Dar et al., 2017; Raza et al., 1978; Khan, 2007). The Himalayas divide the Kashmir valley from the Tibetan plateau while the Pir Panjal range, which encloses the valley from the west and the south, separates it from the Punjab Plain. The study area has a temperate climate with distinct seasonality. The temperature varies from $9{ }^{\circ} \mathrm{C}$ in winter to $38^{\circ} \mathrm{C}$ in summer with an annual rainfall of around $84 \mathrm{~cm}$ (Shafq et al., 2018). The land of the state is highly fertile and water resources are abundant because of its blessed riverine geography. A major portion of the state's terrain is hilly and its height from sea level varies from 1000 feet to 28500 feet (Digest of Economics and Statistics, 2018). The Kashmir Division is revenue and administrative division in the Kashmir Valley region of Jammu and Kashmir. It borders Jammu Division to the south and the union territory of Ladakh to the east, while the Line of Control forms its border with the Pakistan- 
administered territories of Jammu and Kashmir and Gilgit-Baltistan to the north and west, respectively. Srinagar is its city. Other main cities are Baramulla and Anantnag. The Indian administrative districts for the Kashmir Valley were reorganized in 1968 and 2006 each time subdividing existing districts. Kashmir Division currently consists of the following ten districts Anantnag, Kulgam, Pulwama, Shopian, Budgam, Srinagar, Ganderbal, Bandipora, Baramulla, Kupwara (Behera, 2007).

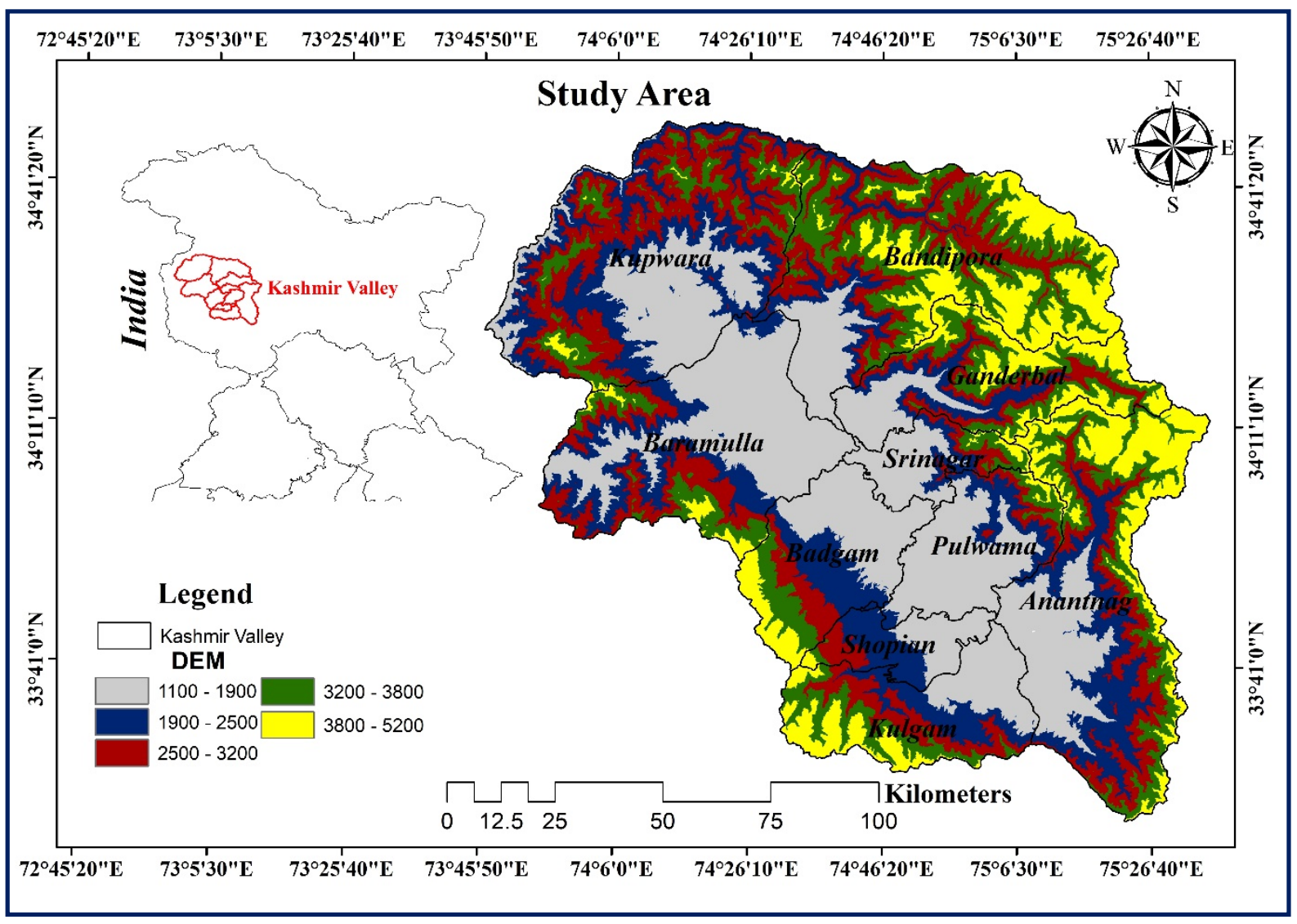

Figure 1 Study Area map

\section{Methodology}

\subsection{Data Collection}

This paper leverages a mix of primary and secondary data sources. The main source of secondary data used herein is the National Census Data, 2011 (conducted every 10 years by the Government of India through its Ministry of Home Affairs). The census data helped identify benchmarks of demographic and socio-economic indicators for the target study area. For collecting primary data, a structured cum semi-questionnaire was devised and used for conducting a field survey across the sample area. While preparing the questionnaire, methodological triangulation has been adopted. This method of blended qualitative and quantitative approach helps in providing confirmation of findings, more comprehensive data, and increased validity of studied phenomena.

\subsection{Data Analysis}

The present analysis of occupational distribution of the female population is based on primary and secondary survey as highlighted above. Before devising any methodology, a pilot survey with the help 
of secondary sources (census, 2011) was done to categorize the large sample area into simpler classes. $5 \%$ of the total villages have been taken and with the help of purposive stratified sampling Female occupational data has been extracted and classes made on the basis of highest and the lowest range using the secondary source (census, 2011). To select the sample size, Cochran's Formula (Formula 1 below) was used for large sample size:

$$
n_{0}=\frac{z_{p}^{2} q}{e^{2}}
$$

(Formula 1: Cochran Formula)

Where $\eta_{0}=$ Sample Size

$z^{2}=$ Value at a given confidence level

$P=$ Estimated proportion of an attribute

$q=1-\mathrm{P}$

$e^{2}=$ Estimated marginal error.

A $10 \%$ non-response rate is assumed here and added to the final sample.

Sampling Methodology

$$
\begin{aligned}
& \text { Sample size }=384 \\
& 384+10 / 100=422
\end{aligned}
$$

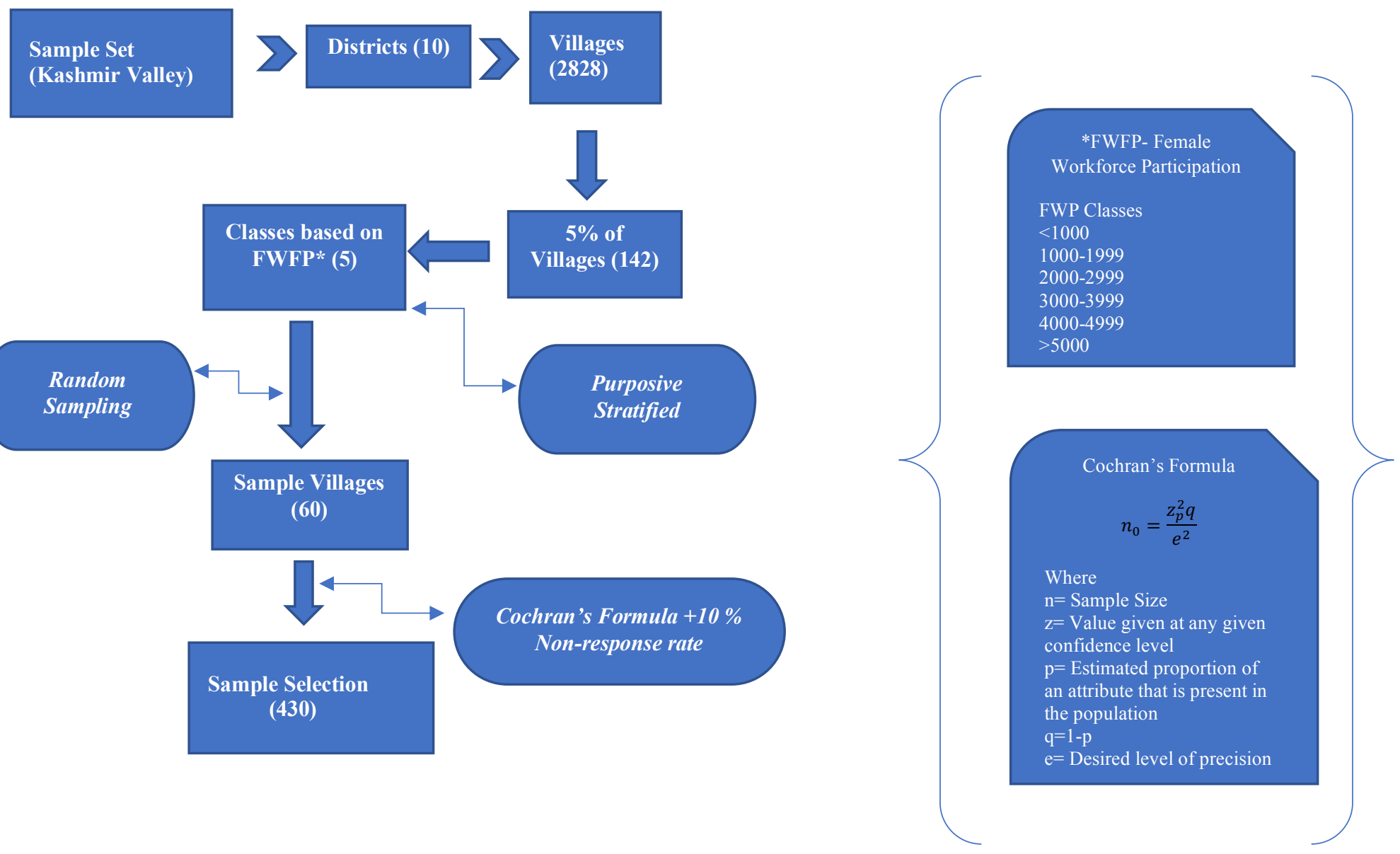


Based on the responses from the sample population, the prevalence of various occupational categories across the sample area (district-wise) was recorded. Geographers and other workers in the urban sphere have given considerable weightage to the question of classification, and the general trend of thought has been if an occupation is concentrated in a town to such a level that it dominates the town's economic activity, then that occupation will be its major function (Daniel et al., 1961). However, this leads to possibilities of overshadowing the degree of variation, thus, limiting our understanding of the representative occupational categories in the target study area. As a consequence of that several functional classifications of regions have been adopted. But perhaps the most successful scientific classification was that worked out by (Nelson, 1961) estimating the degree of variation, which can be described and measured in several alternative ways of which the most popular and most fundamental is the standard deviation referred to as SD (Gregory, 2014). The idea behind the standard deviation (SD) method is to limit the number of towns in any one of occupations to those which are outstanding in providing that service; Otherwise, if a simple technique of percentages is used of the marginal towns or even those below the margin will be included (Nelson, 1961). The SD method (formula 2) employs a mathematical construct to represent the degree of variance within the data under study -

$$
S D=\sqrt{\frac{\sum(x-\underline{x})^{2}}{n}}
$$

\section{(Formula 2: Standard Deviation Calculation)}

where:

$S D=$ standard deviation.

$x=$ individual values of the numbers included in the calculation.

$\underline{x}=$ arithmetic average of various values of $\mathrm{x}$.

$\bar{\Sigma}=$ summation of all values of $\mathrm{x}$.

$n=$ the number of items considered.

Taking inspiration from the SD method, Standard deviations from the average were prepared for each occupational category have been recorded in Table 1 . The variations from the average were recognized and the degree of variation as a factor of SD is also recorded. The districts in the target study area were therefore put in their proper categories and ranked based on their SD scores. Two observations were recorded here for each district in terms of the prevalence of a particular occupational category; (a) Their deviation from the SD for that occupational category e.g., $1 S D, 2 S D$, $3 S D$, and (b) Their deviation in terms of higher representation or lower representation i.e., more than SD or less than SD. Districts that had more than average representation in primary sector, for instance, were given ranking over $+1 S D,+2 S D,+3 S D$, denoted as $P 1(p), P 2(p), P 3(p)$ ranking. Similarly, districts with less than average representation in primary sector were given ranking as $-1 S D,-2 S D,-3 S D$, denoted as $P 1(n)$, $P 2(n), P 3(n)$. Higher the ranking of a district in providing a certain function, higher would be its significance within that category. The same procedure has been followed for each occupational category and each district has thus been encoded to depict the occupational diversification and provide a ranking for the same. It is important to mention that the $N \boldsymbol{A}$ category in the table is referred to housewives. This section is included in the section because the researchers believe that housewives also play a vital role in adding monetary value to the economic system. 


\section{Results}

The target study area, as detailed in the methodology above, was broken down into representative sample villages.

A sample village map highlighting the sample area is covered in Figure 2.

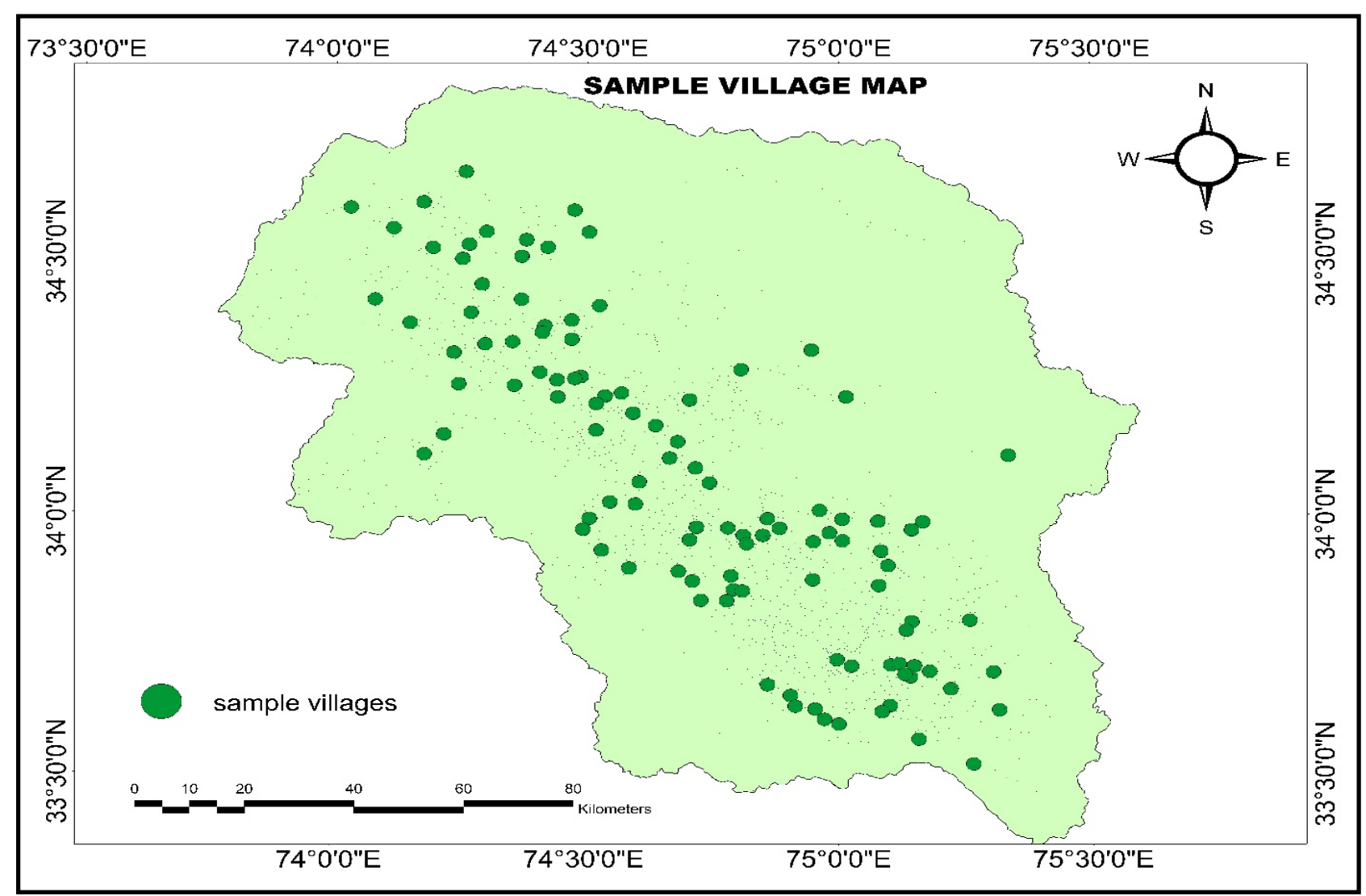

Figure 2 Location map of the surveyed villages in Kashmir valley.

Based on the findings from the sample area, the occupational distribution of female workforce has been charted. Under the occupational categories, as specified earlier, housewives have also been given due consideration along with primary, secondary, tertiary, quaternary and quinary sectors. It was found that women participation in workforce encompasses all sectors, which indicates an improvement in female representation. On the aggregate level, it was observed that the female populace in the valley is largely engaged in tertiary activities, followed by a large segment serving as housewives, closely followed by females engaged in skilled quaternary activities, largely in the medical and research fields. In the study area, however, stark differences were observed in the distribution of female workforce across the sectors. For instance, Ganderbal exhibited a higher concentration of workforce in the primary and secondary sectors, 55 percent and 33 percent respectively. On the other hand, Srinagar saw the majority of respondents engaged in the tertiary, quaternary \& quinary sectors, 52 percent, 13 percent and 10 percent respectively.

The detailed distribution of female workforce across the sectors in the districts of the valley is summarized in Figure 3. 


\section{Occupational Distribution Across DIstricts}

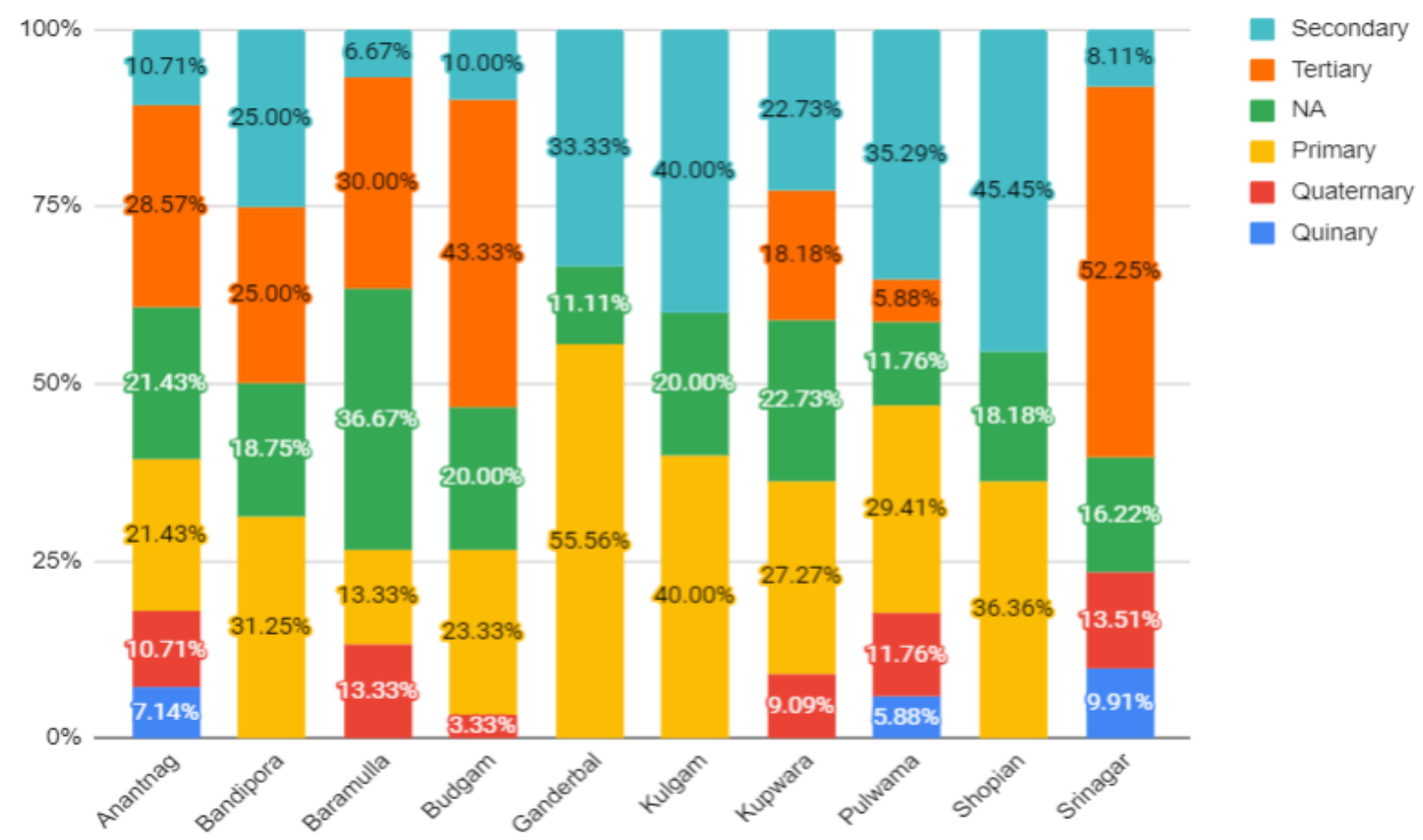

Figure 3 Occupational distribution across districts

As detailed in the Methodology section, the percentage distribution recorded above was transformed into an SD model to gauge the degree of variation and thereby arrive at a holistic representation in the form of an occupational coding pattern. The SD and average calculations for the occupational categories based on the results in Figure 2 have been recorded in Table 1.

Table $1 \%$ age SD Calculation for Each Occupational Category

\begin{tabular}{lcccccccc}
\hline $\begin{array}{l}\text { Occupational } \\
\text { Classification }\end{array}$ & $\begin{array}{c}\text { Average } \\
\%\end{array}$ & S. D & Av-1SD & Av+1SD & Av-2SD & Av+2SD & Av-3SD & Av+3SD \\
\hline Primary & 27.79 & 12.2 & 15.59 & 39.99 & 3.39 & 52.19 & -8.81 & 64.39 \\
Secondary & 23.73 & 14.37 & 9.36 & 38.1 & -5.01 & 52.47 & -19.38 & 66.84 \\
Tertiary & 20.32 & 15.36 & 4.96 & 35.68 & -10.4 & 51.04 & -25.76 & 66.4 \\
Quaternary & 6.18 & 3.79 & 2.39 & 9.97 & -1.4 & 13.76 & -5.19 & 17.55 \\
Quinary & 2.29 & 2.06 & 0.23 & 4.35 & -1.83 & 6.41 & -3.89 & 8.47 \\
Housewives/NA & 19.68 & 7.09 & 12.59 & 26.77 & 5.5 & 33.86 & -1.59 & 40.95
\end{tabular}

When applying the SD method to the villages of 10 districts of Kashmir Valley, some districts have shown more than one type of occupation in relatively outstanding proportions. The results give more validity to the technique 
used, because in real life some occupations are and therefore may exist side by side. Below is a rank table (Table 2) highlighting the representation of occupational distribution for the female workforce across the 10 districts of the valley using the SD method applied on the responses collected from the respondents.

Table 2 Occupational ranking of sample area using the SD Method

\begin{tabular}{lcccccc}
\hline District & Primary & Secondary & Tertiary & Quaternary & Quinary & Housewives \\
\hline Anantnag & P1(n) & S1(n) & T1(p) & Qt2(p) & Qi2(p) & H1(p) \\
Bandipora & P1(n) & S1(p) & T1(p) & - & - & H1(n) \\
Baramulla & P2(n) & S2(n) & T1(P) & Qt2(p) & - & H3(p) \\
Budgam & P1(n) & S1(n) & T2(p) & Qt1(n) & - & H1(p) \\
Ganderbal & P3(p) & S1(p) & - & - & - & H2(n) \\
Kulgam & P2(p) & S2(p) & - & - & - & H1(p) \\
Kupwara & P1(n) & S1(n) & T1(n) & Qt1(p) & - & H1(p) \\
Pulwama & P1(p) & S1(p) & T1(n) & Qt2(p) & Qi2(p) & H2(n) \\
Shopian & P1(p) & S2(p) & - & - & - & H1(n) \\
Srinagar & - & S2(n) & T3(p) & Qt2(p) & Qi3(p) & H1(n) \\
\hline
\end{tabular}

\section{Discussion}

\subsection{Primary Sector}

Kashmir valley has been a fruit-growing region from ancient times. Horticulture is an old economic activity in the state. Kalhana, the great Kashmiri historian has mentioned fruit culture in Kashmir in his book "Rajtarangini" during the region of King Nara as back as 1000 B.C. Kashmir Valley, as per the survey results, primary sector is seen mostly across the valley with a larger concentration in Ganderbal and Kulgam with no such exception. According to the census 2011, female employment in Primary sector is majorly seen in agriculture in both the districts. In Kulgam district the total percentage of cultivators is $36.48 \%$ and agricultural labourers is $33.12 \%$. Ganderbal district has $28.6 \%$ as cultivators and $21.87 \%$ as agricultural labourers. It is noteworthy to mention here that women are not free as men to participate in the formal economy due to social limits. This implies that most part women workforce is engaged in lower-skilled and semi-skilled with low wages and are not owners of capital. Generally, female cultivators are members of a family that owns the land, rather than being the owners (Alam, 2020). Also, the impact of agricultural commercialization on women employment in primary sector cannot be ignored. District Ganderbal and Kulgam are best known for their maize and paddy cultivation. Kulgam which was famous for the rice productivity once used to be called the rice bowl of Kashmir is now amongst the lowest producers of rice (Raina, 2002). Paddy land is getting converted into horticultural land as farmers seek to earn more revenue against horticultural products (Reshi et al., 2010; Ganaie et al., 2014; Shah, 2017). In this agricultural commercialization of cash crops, the specific impact on women's employment and social position has been relatively neglected. Much of the available literature is based on the African experience in which the 
conclusion has been that women had an increase in their work burden along with a fall in their nutritional standard (shifting from yam to cassava) and no gain in their control over cash income (Bukh, 1979; Mbilinyi, 1972; Palmer, 1977). In the Indian context, there are virtually no studies on the employment effect of this shift to cash crops. In such a situation, the introduction of certain cash crops may have a very positive impact on employment. For example, the introduction of cigarette tobacco in the early twenties had a dramatic impact on female labour as tobacco cultivation was largely dependent on female labour for transplanting, weeding, harvesting and curing (Mies, 1984).

\subsection{Secondary Sector}

As per the survey results, Shopian, Kulgam, Pulwama and Ganderbal show positive variations in female representation in secondary sector. This could be because the main household industries employing female workforce are found in the above-mentioned districts. Household industries involved in shawl making, chain stitch, kangri making (earthen hot pots), Namda (handmade woolen rug), Jam Making, packing of fruits, walnuts and spices are abundantly found in Pulwama and Ganderbal. In fact, handicrafts have been in practice for centuries in the State. With the introduction of 'Kangri' artisans could not remain contented with this item alone and took to manufacturing of other items like, 'Kranjlu, 'Photri' (rough baskets), 'Dakri' and 'Tokri' (baskets for lifting domestic articles) and thus displayed extra-ordinary skill and workmanship in diversifying its productivity. In other parts of the valley, especially in Ganderbal and Srinagar areas, fine types of basketry weaving came to be adopted. The craftsmen of Srinagar and Ganderbal areas are manufacturing various types of furniture articles like chairs, tables, teapots besides cycle baskets for carrying goods of light weights (Census, 1981). Some of these like Gabba and blanket making are well-known Kashmiri heritage popularized since long. These support the findings from the survey especially given that these see higher traction amongst the females, also giving employment opportunities to the Kashmir female workforce.

\subsection{Tertiary sector}

Srinagar District dominates the sector followed by Budgam, Anantnag, Baramulla and Bandipora. Being the Summer capital of the State, Srinagar city is composed of higher service sectors like tourism, trade and commerce and employment in the government sector. Anantnag being in the midst of the trade route connecting the valley with rest of the states, therefore, shows a positive variation.

\subsection{Quaternary and Quinary Sector}

Due to the limited availability of the data in these two sectors the abundance was found in three districts namely Srinagar, Anantnag and Pulwama. Srinagar city, the only Metropolis of the J\&K state, constitutes around twothird of the state's urban population and is two times larger than the second largest city of the state- Jammu. Srinagar, a primate and characteristically diversified as well as unique city, unanimously serves as a regional centre in the vast catchment and is not only the largest urban centre both in terms of demographic size and areal spacing but also rapidly growing city amongst all Himalayan urban centres (Yousuf et al., 2017). It is clearly seen that the high income in urban areas and low income in rural areas in addition to the prevalence of specialized institutions herein acted as the pull and push factors for the economic development of the city thereby providing job opportunities in both the private and government sectors. Similarly, for Pulwama the positives from the 
developed industrial belt seem to have aided growth in higher sectors with focus on education and skill development.

\subsection{Housewives}

The distribution of housewives, as expected, was significant across the study area. However, an interesting facet emerged from the districts of Ganderbal \& Pulwama, where a larger fraction of women were engaged in other sectors as well. This could be owing to the structured engagement of women here in the secondary sector, given the opportunities in the light of well-established industrial estates. The researcher has accounted for housewives separately within designated occupational categorization owing to the belief that this section plays a pivotal role in shaping the overall society. Be it their role as housemakers, or as nurturing mothers, or as the manager of household affairs, housewives contribute to society in more ways than one could attribute. 'In 2001 census housewives were clubbed with beggars, prostitutes, prisoners who according to the census were not involved in any economic activity. In 2010, the Supreme court of India criticized the census body by issuing a statement which said “Housewives Are an Invaluable Unpaid Resource and Definitely Not Unproductive!'. Managing domestic help can be a full-time job in itself and doesn't substitute for the everyday drudgery of housework that a housewife still performs. She's everything to everyone - the dutiful wife, caring mother and daughter-in-law; the cook, cleaner, and manager' (Guruprasad, 2016).

\section{Problem Statement}

A handicap observed in concluding the current study is the lack of existing statistical data to compare the findings across the identified occupational sectors. Furthermore, given the limitation of reliance on primary data, factors like inter-district migration and commuting for work on a daily basis, could not be ignored and may reflect in the findings above.

\section{Conclusion}

Women share in formal and informal labor market has gained much importance at national and international level. It has become the main agenda of national and international organizations for last three decades. However, collecting data for women who are contributing to the household income through their economic activities is a Herculean task (Awan et al., 2015). Female contribution to the informal sector is often neglected. Singh et al., (2012) stated that the role of women in agriculture as female labour is not highlighted in India. Despite of their presence in agricultural activities regarding sowing, transplanting and post-harvest operations they are considered as an invisible worker. In truth, women are involved in all aspects of agriculture, from crop selection to land preparation, to seed selection, planting, weeding, pest control, harvesting, crop storage, handling, marketing, and processing (Ghosh et al., 2014). Same is the scenario with the other sectors as well. Whatever the reason for this neglect, the importance of occupational categorization of female workforce based on the services they render is of utmost importance. The SD method adopted in this paper is a way forward in this approach and has led to a satisfactory methodical representation of the occupational distribution observed in the sample area. The occupational coding of the target districts using this method not only makes it easier to visualize the occupational trends but also gives us a clear sense of variation (positive and negative) amongst these categories across the districts. Focus on occupational categorization can be helpful for the study of other related aspects like female 
occupational health and environment as well. Cheng et al., (2000) while studying the association between psychosocial work characteristics and health functioning in American women stated that the women in jobs with high demands, low control, and low social support ("iso-strain" jobs) showed the greatest declines in health status and functioning. Towards this end, the systematic approach adopted for occupational categorization and the results therefrom will not only help in understanding the needs better \& aid in empowering women as well as to attain related sustainable development goals.

Acknowledgment The first two authors (Aisha Dev and M. Imran Ganaie) express gratitude to the University Grants Commission, New Delhi, India for providing financial assistance.

\section{Declarations}

Conflict of Interest The authors declare that they have no conflict of interest.

Ethical Approval This work was performed with the involvement of human participation. All the interests of the participants were taken into consideration during the primary survey and the work was approved by the Department of Geography, University of Kashmir, India, 190006.

\section{References}

1. Agarwal, B. (1985). Work participation of rural women in third world: Some data and conceptual biases. Economic and Political weekly, A155-A164.

2. Alam, S. PERFORMANCE OF WOMEN'S WORK CONTRIBUTION IN AN INDIAN ECONOMY.

3. Awan, A. G., Faridi, M. Z., \& Abbas, M. (2015). Factors affecting women contribution in household budget in urban informal sector: An analysis. Journal of Human-Social Science, 15(1), 4-15.

4. Behera, N. C. (2007). Demystifying Kashmir. Brookings Institution Press.

5. Bukh, J. (1979). The village woman in Ghana (No. 1). Nordic Africa Institute

6. Census of of India, 1961 Monograph series, Monograph Number 4, also ex- cludes female workers altogether on the ground that "their participation in various types of work cannot be closely gauged from the Census".

7. Cheng, Y., Kawachi, I., Coakley, E. H., Schwartz, J., \& Colditz, G. (2000). Association between psychosocial work characteristics and health functioning in American women: prospective study. Bmj, 320(7247), 1432-1436.

8. Daniel and Alice Thorner, "Land and Labour in India", Asia Publishing House, 1961, p 75;

9. Dar, R. R. (2017). Tourism and Management of Wetland Ecosystems in Kashmir Valley (Doctoral dissertation, Aligarh Muslim University).

10. Duvvury, N. (1989). Women in agriculture: a review of the Indian literature. Economic and Political Weekly, WS96-WS112.

11. El-Bushra, E. S. (1969). Occupational classification of Sudanese towns. Sudan Notes and Records, 7596

12. Ganaie, S. A., Bhat, M. S., \& Parry, J. A. (2014). Spatial Variations in the Levels of Agricultural and Socio-economic Development in Jammu \& Kashmir-A District Level Analysis. Agricultural Economics Research Review, 27(1), 119-126. 
13. Gani, A. (2016). Hadicraft Suvey Report Kangri \& Willow Wicher Basketry, Part XD, Series-8

14. Ghosh, M., \& Ghosh, A. (2014). Analysis of women participation in Indian agriculture. IOSR J. Human. Soc. Sci, 19(5), 1-6.

15. Gregory, S. (2014). Statistical methods and the geographer. Routledge.

16. Gulati, L. (1975). Occupational Distribution of Working Women An Inter-State Comparison. Economic and Political weekly, 1692-1704.

17. Guruprasad, M. (2016) Economics for Everyone: Evaluating Economic Activity-Home Economics Housewives Contribution to the Economy. https://syr.us/mH7.

18. Joseph E Schulzberg, in his Monograph on "Occupational Structure and Level of Eronomic Development in India: A Regional Analysis",

19. Katz, M. B. (1972). Occupational classification in history. The Journal of Interdisciplinary History, 3(1), 63-88.

20. Khan, A. R., 2007. Geography of Jammu and Kashmir. Gulshan Books, Srinagar- 190001 Kashmir.

21. Kumar, A., \& Meher, S. (2018). Trends of occupational pattern in India: An analysis NSSO. International Journal of Research in Social Sciences, 8(1), 463-476.

22. Mbilinyi, M. J. (1972). The state of women in Tanzania. Canadian Journal of African Studies/Revue Canadienne des Études Africaines, 6(2), 371-377.

23. Mies, M. (1980). Capitalist development and subsistence reproduction; rural women in India. Bulletin of Concerned Asian Scholars, 12(1), 2-14.

24. Nelson, H. J. (1961). Walled cities of the United States. Annals of the Association of American Geographers, 51(1), 1-22.

25. Palmer, I. (1977). Rural women and the basic-needs approach to development. Int'l Lab. Rev., $115,97$.

26. Raina, A. N. (2002). Geography of Jammu \& Kashmir State. Radha Krishan Anand \& Co., Pacca Danga, Jammu.

27. Raza, M., Ahmad, A., \& Mohammad, A. (1978). The Valley of Kashmir: A Geographical Interpretation. Vol. 1: The land. Vikas.

28. Reshi, M. I., Malik, M. A., \& Vijay, K. (2010). Assessment of problems and prospects of apple production and marketing in Kashmir valley, India. Journal of Environmental Research and Development, 4(4), 1077-108

29. Shafiq, M. U., Rasool, R., Ahmed, P., \& Dimri, A. P. (2019). Temperature and precipitation trends in Kashmir Valley, north western Himalayas. Theoretical and Applied Climatology, 135(1), 293-304.

30. Shah, M. A. (2017). Association of the socio-economic variables and the price fixing of Paddy produceA case study of District Kulgam, Jammu and Kashmir. Review of Research, 7.

31. Yousuf, T., Yousuf, T., \& Shah, S. A. (2017). URBAN HOUSING DYNAMICS OF SRINAGAR METROPOLIS: A STUDY IN HOUSING GEOGRAPHY. 